\title{
Effects of Naltrexone on Smoking Cessation Outcomes and Weight Gain in Nicotine-Dependent Men and Women
}

\author{
Andrea C. King, PhD, * Dingcai Cao, PhD,† Stephanie S. O’Malley, PhD, $\neq$ Henry R. Kranzler, MD, $\S$ \\ Xiaochen Cai, MS, * Harriet deWit, PhD, * Alicia K. Matthews, PhD,// and Ryan J. Stachoviak, MPH*
}

\begin{abstract}
This study examined whether the opioid receptor antagonist naltrexone is efficacious in smoking cessation and whether sex moderates the response. We assessed smoking quit rates and weight gain in a double-blind randomized trial comparing oral naltrexone $(n=162)$ with placebo $(n=154)$ in nicotine-dependent participants who wanted to quit smoking. The medication was gradually titrated up to $50 \mathrm{mg}$ during the week before the quit date and then maintained at this dose for 12 weeks. For the first 4 weeks after the quit date, all participants received a nicotine patch to mitigate tobacco withdrawal and attended weekly individual cognitive-behavioral smoking cessation counseling sessions. After this time, participants continued with naltrexone or placebo through 12 weeks. Follow-up assessments were conducted at 26 and 52 weeks. During treatment, naltrexone (vs placebo) increased quit rates, attenuated smoking urge, and reduced weight gain. At follow-up, after medication discontinuation, the effect of naltrexone on improving quit rates was no longer evident. Men and women experienced different benefits from naltrexone; men showed greater reductions in smoking, whereas women showed greater reductions in weight gain. In sum, naltrexone showed acute efficacy in treating nicotine dependence, but after the medication was discontinued, the effect on quit rate was not maintained. Further study of naltrexone in smoking cessation treatment and reduction of cessation-related weight gain, as well as preclinical investigation of mechanisms underlying sex differences, is warranted.
\end{abstract}

Key Words: naltrexone, smoking cessation, nicotine dependence, weight gain, quit rates, sex differences, sex differences

(J Clin Psychopharmacol 2012;32: 630-636)

C urrently, $20.6 \%$ of adults in the United States smoke cigarettes and cigarette smoking continues to be the leading preventable cause of death. ${ }^{1,2}$ The currently approved pharmacotherapies for tobacco dependence, including nicotine replacement, bupropion, and varenicline, double or triple smoking

From the Departments of *Psychiatry \& Behavioral Neuroscience, $\uparrow$ Ophthalmology and Visual Science, University of Chicago, Chicago, IL; $\$$ Yale University School of Medicine, New Haven, CT; §University of Pennsylvania, Philadelphia, PA; and $\|$ College of Nursing, University of Illinois at Chicago, Chicago, IL.

Received August 15, 2011; accepted after revision February 16, 2012.

Reprints: Andrea C. King, PhD, Department of Psychiatry,

University of Chicago, $5841 \mathrm{~S}$ Maryland Ave (MC-3077),

Chicago, IL 60637 (e-mail: aking@bsd.uchicago.edu)

This study was supported by grants from the National Institute of Drug

Abuse/the National Institutes of Health (R01-DA016834), CTSA Grant

Number ULI-RR024999 from the National Center for Advancing

Translational Sciences (its contents are solely the responsibility of the

authors and do not necessarily represent official views of the National

Center for Advancing Translational Sciences or the National Institutes of

Health), and the National Cancer Institute (P30-CA14599).

Supplemental digital contents are available for this article. Direct URL

citations appear in the printed text and are provided in the HTML

and PDF versions of this article on the journal's Web site

(www.psychopharmacology.com)

Copyright (C) 2012 by Lippincott Williams \& Wilkins

ISSN: 0271-0749

DOI: $10.1097 / \mathrm{JCP} .0 \mathrm{~b} 013 \mathrm{e} 3182676956$ abstinence rates compared with placebo. ${ }^{3}$ Nevertheless, only a minority of smokers who receive these pharmacotherapies are able to quit smoking (ie, $19 \%-33 \%$ quit rates at 6 months). ${ }^{3}$ Additional medications are needed to treat patients for whom the existing treatments are ineffective or contraindicated.

Opioid receptors and ligands play an important role in brain reward processes and modulate nicotine-induced dopamine release in brain regions linked to addictive processes. ${ }^{4}$ There is preliminary evidence that naltrexone, a primarily $\mu$-opioid receptor antagonist approved for the treatment of both opioid and alcohol dependence, may be efficacious for the treatment of tobacco dependence, particularly in combination with the nicotine patch. ${ }^{5,6}$ It is likely that naltrexone and nicotine replacement have complementary mechanisms of action, with the former altering cigarette reward and reinforcement ${ }^{7}$ and the latter attenuating tobacco withdrawal. ${ }^{8}$ However, not all studies support the efficacy of naltrexone in smoking cessation, either alone ${ }^{9}$ or to augment the effects of the nicotine patch. ${ }^{9,10}$ Indeed, Clinical Practice Guidelines ${ }^{3}$ and the 2009 Cochrane Report ${ }^{11}$ concluded that, based on limited data from 4 trials, it is not possible to draw firm conclusions on whether naltrexone helps people quit smoking and "data from larger trials of naltrexone are needed to settle the question of efficacy for smoking cessation." 11 The inconclusive results may be due in part to methodological and dosage differences across studies and individual variability including sex differences. There is some evidence that naltrexone, administered along with short-term nicotine patch or alone, has greater efficacy in women ${ }^{5,12,13}$ who historically show lower quit rates than men do to nicotine replacement therapy. ${ }^{14,15}$ Although the source of potential sex differences is unknown, differences between men and women have been postulated for drug metabolism, availability and sensitivity of opioid receptors and their distribution, and the effects of sex and stress hormones to opioid responsivity. ${ }^{16-19}$

Another important problem in the treatment of nicotine dependence is that smokers frequently gain weight when they quit smoking, which can interfere with their willingness to make a quit attempt. ${ }^{3}$ Nicotine increases metabolism and suppresses appetite, ${ }^{20}$ and many smokers report smoking cigarettes in place of eating, including at the end of a meal. ${ }^{21}$ The weight gain associated with quitting smoking may be particularly salient for women, as they exhibit significantly greater weight concerns than men $\mathrm{do}^{22}$ and are more likely to discontinue a quit attempt because of such concerns. ${ }^{23}$ Several currently approved smoking cessation medications, including bupropion and the nicotine gum and lozenge, have been shown to delay but not prevent postcessation weight gain. ${ }^{3}$ Naltrexone might be particularly important in this regard because brain opioid systems are critically involved in food reward through hedonic and incentive motivation circuits ${ }^{4,24}$ and opioid antagonists acutely alter food pleasantness ratings and other appetitive aspects of eating and binge eating behaviors. ${ }^{25}$ Interestingly, in 2 studies, smokers treated with naltrexone for 4 to 6 weeks gained less weight than those treated with placebo. ${ }^{5,6}$ The effect of naltrexone on 
weight gain over longer intervals is unknown, as the only study thus far reporting weight at longer-term intervals used low-dose naltrexone (25 mg daily) and showed directional but nonsignificant weight gain reduction versus placebo at 6 months. ${ }^{9}$ Additional studies are needed to more fully address this question.

The present study compared the efficacy of oral naltrexone $(50 \mathrm{mg} / \mathrm{d})$ to that of placebo in treating nicotine dependence. The dosage was chosen as it is the US Food and Drug Administration (FDA)-recommended therapeutic dose for alcohol dependence, its adverse effects are modest compared with higher dosages, ${ }^{6}$ and it is sufficient to produce near-complete inhibition of brain $\mu$-opioid receptors. ${ }^{26}$ As opioid antagonists may increase tobacco and narcotic-like withdrawal effects during early smoking abstinence, ${ }^{27}$ and tobacco withdrawal usually subsides during the first several weeks of cessation, ${ }^{28}$ an openlabel treatment with nicotine patch was included through the first 4 weeks after the quit date. Given the dearth of clinical trial research with naltrexone for smoking cessation, our main focus was to examine the effects of naltrexone on smoking and weight outcomes during a short-term treatment for 12 weeks after the smoking quit date. This interval represents the longest period examined to date at the $50-\mathrm{mg}$ dose for nicotine dependence, ${ }^{7}$ the phase when relapse is most commonly observed, and the duration recommended by the FDA for pharmacotherapies for nicotine dependence. Patient adherence also usually remains high for this period.

Our primary hypothesis was that naltrexone would increase end-of-treatment smoking quit rates and decrease weight gain associated with abstinence. On the basis of prior research, $5,12,13$ we also predicted that these effects would be more pronounced in women than in men. Secondary analyses examined quit rates after medication discontinuation, that is, at 26- and 52-week follow-up. The strengths of this study compared to those of prior studies include (1) a large sample size with adequate power to detect medication effects, (2) a priori stratification for sex, and (3) a 1-week dose titration before the quit date to reduce adverse effects and to serve as a potential extinction period of cigarette reinforcement. $^{29}$

\section{MATERIALS AND METHODS}

\section{Participants}

Participants were enrolled at 3 sites within the Chicago area, including the University of Chicago $(n=184)$, the Respiratory Health Association of Metropolitan Chicago $(\mathrm{n}=82)$, and the Howard Brown Health Center $(n=49)$. Internet, print, and radio advertisements were used to recruit participants. At the screening visit, eligible candidates gave their consent after procedures and possible adverse effects were explained to them. The protocol was approved by The University of Chicago Institutional Review Board. The candidates then received a physical and psychological examination (for details, see King et $\mathrm{al}^{30}$ ). Subjects were eligible if they were 18 to 65 years old, smoked 10 to 40 cigarettes daily for at least 2 years, had a body mass index of 19 to $38 \mathrm{~kg} / \mathrm{m}^{2}$, had a breath carbon monoxide reading of at least $10 \mathrm{ppm}$, and a urinary Nicalert reading greater than $500 \mathrm{ng} / \mathrm{mL}$ cotinine, confirming regular smoking. Candidates were excluded if they had a past-year history of a major medical or psychiatric disorder, substance dependence (except nicotine) or a lifetime diagnosis of opioid abuse or dependence, use of opioid or psychotropic medications, elevated hepatic transaminase concentrations $(>2.5$ times the reference range), or were unable to read or write English. Breast-feeding or pregnant women were excluded.
At the screening session, candidates completed surveys on demographics, smoking, and substance use history. They also completed a Fagerström Test for Nicotine Dependence ${ }^{31}$ and underwent an interview on a modified version of the Structured Clinical Interview for DSM-IV, nonpatient version. ${ }^{32}$

\section{Procedures}

Subjects were randomly assigned by computer to the 2 treatment conditions (naltrexone or placebo), stratified by sex. Participants and study staff were blinded to treatment assignment. The study included 10 study visits. The first 2 visits took place during the 2 weeks before the quit date, the next 4 visits were scheduled once weekly, and the last 4 visits were tapered to every other week and concluded 12 weeks after quit date. Follow-ups were conducted by telephone at 26 and 52 weeks after the quit date, and those who reported smoking abstinence were asked to attend an in-person visit to provide biochemical confirmation.

The study visits included 20 to 30 minutes of completing surveys and interviews with the research assistant and receiving the study medication(s). This assessment was followed up a 45-minute behavioral counseling session (described later) for the first 6 visits. Participants were compensated for completing study measures at different intervals during active treatment; the total possible compensation including cash and gift cards was $\$ 110$, with a possible additional $\$ 40$ gift card in a random drawing at the end of treatment. For follow-up, the compensation for the telephone interview was $\$ 30$, and for attending an in-person visit to verify abstinence, compensation was $\$ 30$ to $\$ 60$ in gift cards from a random drawing.

\section{Medication Conditions}

Participants received tablets containing naltrexone hydrochloride or placebo (Mallinckrodt Pharmaceuticals, Hazelwood, Mo) at the second visit, with instructions to take their first dose the next morning, 6 days before the quit date. The first naltrexone dose was $12.5 \mathrm{mg}$, the next 2 doses were $25 \mathrm{mg}$ daily, and the fourth dose was $50 \mathrm{mg}$ daily, which was continued through the quit date and the subsequent 12 weeks. Treatment with transdermal nicotine patch (Nicoderm CQ; GlaxoSmithKline, London, UK) was initiated on the quit date and continued daily at $21 \mathrm{mg} / \mathrm{d}$ for the first 2 weeks, followed by $14 \mathrm{mg}$ daily for the third week, and $7 \mathrm{mg}$ daily for the fourth week. The rationale for the short duration of patch in this study was to mimic the median duration of over-the-counter nicotine replacement for most smokers ${ }^{33}$ and to reduce narcotic-like withdrawal symptoms that may occur with opioid receptor antagonists during early smoking abstinence. ${ }^{27}$ Decisions on tablet and patch reductions or discontinuation were determined by the study physician and participant on an individual basis; participants were encouraged to continue in counseling and research follow-up irrespective of whether they chose to continue pharmacotherapies.

Group assignment and early naltrexone compliance were verified via urine samples obtained on the morning of the quit date. Participants were instructed to collect these samples upon awakening, that is, after their first void and ingestion of their tablet. They collected a 3-hour urine sample in a container provided to them, as well as a saliva sample at 90 minutes as a backup for the urine sample. The concentrations of naltrexone and its major metabolite, 6- $\beta$-naltrexol were measured using the Immunalysis Naltrexone Direct ELISA Kit (Immunalysis Corporation, Pomona, Calif) and confirmed by gas chromatography-mass spectrometry (Agilent Technologies, Santa Clara, Calif). 


\section{Counseling}

A master's- or doctoral-level clinician conducted six 45-minute, semistructured, individual behavioral therapy sessions with the participant. Clinicians used a standardized treatment developed by A.K. (Courage to Quit) ${ }^{5,34}$ and were trained and supervised by A.K. This psychosocial treatment is based on evidence-based interventions ${ }^{3}$ and includes cognitive-behavioral, motivational, and 12-step addiction techniques. Participants attended a mean (SD) of 5.5 (1.3) of the 6 counseling sessions, and this did not differ by group or sex.

\section{Assessments}

At each study visit, participants underwent weight measurement, a breath test for carbon monoxide, and a Timeline Follow Back interview ${ }^{35}$ to quantify daily cigarette use and tablet and patch adherence and returned unused medications. Weight was measured by the research assistant with a digital medical scale (Tanita, Tokyo, Japan), and weight values were not shared with the participant to reduce undue stress. The Brief Questionnaire of Smoking Urges ${ }^{36}$ and the Beck Depression Inventory ${ }^{37}$ were also administered at each visit. In addition, during the first 6 visits, the participant completed a 15-item scale assessing opioid antagonist and nicotine patch adverse effects to assess if each effect was experienced in the past week and, if so, whether it was rated as mild or severe.

At 26 and 52 weeks after the quit date, the participant completed a telephone follow-up that included a Timeline Follow Back of daily cigarette use for the preceding 4 weeks and an assessment of medical and psychological conditions. Subjects who reported being smoke-free in the past 7 days were asked to attend an in-person visit for carbon monoxide verification. Follow-up rates were high and did not differ by group or sex (telephone follow-up at 26 weeks, 99\% completion in both groups; at 52 weeks, $98 \%$ placebo vs $96 \%$ naltrexone; in-person follow-up of abstainers at 26 weeks, $95 \%$ vs $89 \%$, respectively; at 52 weeks, $92 \%$ vs $88 \%$ ). Carbon monoxide verification was also high, as only 3 participants at 26 weeks and 2 participants at 52 weeks did not provide a breath test despite repeated attempts by research staff to facilitate this brief test at a convenient location; as per study protocol, they were classified as relapsed to smoking.

\section{Statistical Analyses}

Baseline demographic and smoking characteristics were compared by group and sex using analysis of variance or logistic regression. Adherence was computed as the total proportion of dispensed tablets and patches that were reported taken at each visit. Participants who dropped out were conservatively classified as relapsed to their baseline smoking level on the day of their dropout. Similar to O'Malley et $a l^{6}{ }^{6}$ a missed visit was coded as abstinent if the 2 surrounding visits were verified as abstinent and $2 \%$ of the data was imputed based on this procedure. From the Timeline Follow Back with biochemical verification (carbon monoxide $<10 \mathrm{ppm}$ ), quit status was defined two ways, as both lapse-allowed and as prolonged abstinence. Lapse-allowed abstinence was defined as not smoking even a puff for seven days in a row or on one day in each of two consecutive weeks and prolonged abstinence was defined as not smoking even a puff of a cigarette allowing for a 1 -week grace period. ${ }^{38}$ Using lower carbon monoxide

TABLE 1. Baseline Demographic and Smoking Characteristics

\begin{tabular}{|c|c|c|c|c|}
\hline \multirow[b]{2}{*}{ Variable } & \multicolumn{2}{|c|}{ Placebo } & \multicolumn{2}{|c|}{ Naltrexone } \\
\hline & $\operatorname{Men}(n=71)$ & Women $(n=83)$ & $\operatorname{Men}(n=76)$ & Women $(n=85)$ \\
\hline Age, mean (SD), y & $40.6 *(11.0)$ & $44.3(10.0)$ & $38.2 *(11.3)$ & $44.1(12.0)$ \\
\hline Education (years completed), mean (SD) & $15.1(1.7)$ & $15.0(2.7)$ & $15.4(2.6)$ & $14.8(2.8)$ \\
\hline Hollingshead index, mean (SD) & $46.4(13.5)$ & $46.6(12.8)$ & $46.3(14.8)$ & $45.6(13.8)$ \\
\hline Body mass index, mean (SD), $\mathrm{kg} / \mathrm{m}^{2}$ & $26.7(4.2)$ & $27.1(4.6)$ & $26.9(4.4)$ & $27.3(4.6)$ \\
\hline Cigarettes per day, mean (SD) & $21.7 \dagger(7.6)$ & $19.1(5.5)$ & $19.0(5.2)$ & $19.2(5.5)$ \\
\hline Age of smoking initiation, mean (SD) & $15.0(3.4)$ & $14.8(3.6)$ & $15.2(3.5)$ & $15.2(4.6)$ \\
\hline Carbon monoxide level, mean (SD), ppm & $24.8(15.2)$ & $24.0(10.9)$ & $23.0(10.5)$ & $21.3(11.1)$ \\
\hline Nicotine dependence (FTND), mean (SD) & $5.5(1.7)$ & $5.3(1.8)$ & $4.8(1.7)$ & $5.3(1.8)$ \\
\hline Smoking urge (BQSU), mean (SD) & $28.5(11.8)$ & $28.7(11.4)$ & $29.9(9.9)$ & $30.9(11.6)$ \\
\hline No. past quit attempts ( $>12 \mathrm{~h})$, mean (SD) & $4.4(5.1)$ & $3.8(6.4)$ & $5.5(13.9)$ & $3.8(3.7)$ \\
\hline \multicolumn{5}{|l|}{ Race, $\mathrm{n}(\%)$} \\
\hline Caucasian & $46(64.8)$ & $47(56.6)$ & $44(57.9)$ & $44(51.8)$ \\
\hline African American & $22(31)$ & $30(36.2)$ & $20(26.3)$ & $38(44.7)$ \\
\hline Asian & $1(1.4)$ & $1(1.2)$ & $5(6.6)$ & $1(1.2)$ \\
\hline More than 1 race/other & $2(2.8)$ & $5(6)$ & $7(9.2)$ & $2(2.3)$ \\
\hline Ethnicity (non-Hispanic), n (\%) & $67(94.4)$ & $80(96.4)$ & $73(96.1)$ & $83(97.6)$ \\
\hline Married or living with partner, n (\%) & $25(35)$ & $25(33)$ & $28(34)$ & $24(28)$ \\
\hline Sexual preference for opposite sex, $n(\%)$ & $60(85.7)$ & $76(91.6)$ & $61(81.3)$ & $78(91.8)$ \\
\hline Current alcohol drinker, n (\%) & $60(87)$ & $71(90)$ & $69(93)$ & $72(86)$ \\
\hline
\end{tabular}

Current alcohol drinker defined as consuming at least one drink in past six months.

*Drinks per week were analyzed taking into account the participants' body water estimates.

$\dagger$ Sex difference, $P<0.05$.

BQSU indicates Brief Questionnaire of Smoking Urges; FTND, Fagerström Test of Nicotine Dependence. 
verification levels (ie, $5 \mathrm{ppm})^{39}$ did not affect results and only changed 1 participant's end-of-treatment quit status classification for either criteria. Kaplan-Meier survival curves were estimated in the groups, and quit rates during treatment were analyzed by a Wilcoxon (Breslow) test that gave more weight to early failures.

Secondary analyses of other smoking outcomes included time to first cigarette, number of cigarettes smoked weekly throughout the treatment, and smoking urge ratings. These secondary outcomes complemented the main quit rate outcomes and enabled a more complete picture of overall smokingrelated behaviors. The $t$ tests were used to examine time to first cigarette (in the $77 \%$ of participants who smoked at least 1 cigarette throughout the trial) and weight gain. Generalized estimating equation ${ }^{40}$ models were used to compare groups over time on the weekly number of cigarettes smoked and smoking urge. Because of data skewness, the weekly numbers of cigarettes data were log transformed for analysis. Finally, logistic regression analyses were conducted on long-term quit rates at weeks 26 and 52 .

\section{RESULTS}

\section{Enrollment and Subject Characteristics}

Participants were enrolled from June 15, 2006, to March 12, 2009, with follow-ups completed by April 19, 2010. The Supplementary Figure A (Supplemental Digital Content 1, http://links.lww.com/JCP/A140) depicts the flow of participants. The intent-to-treat sample included the 315 participants ( $94 \%$ of those initially enrolled) who ingested at least the first dose of study medication on the day after the second visit. The 12-week completion rates did not differ by group (placebo, $115 / 154$ participants [75\%]; naltrexone, 123/161 participants [76\%]). Self-reported tablet and patch adherence was greater than $75 \%$, and there were no treatment group or sex differences. Most participants complied with urine and/or saliva collection on the quit date (placebo, 94\%; naltrexone, 91\%). Confirming group assignment, $100 \%$ of placebo-treated participants were negative and $96 \%$ of naltrexone-treated participants were positive for naltrexone or 6- $\beta$-naltrexol levels.

Table 1 depicts the baseline characteristics of participants. The sample was racially diverse, with $57 \%$ whites, $35 \%$ African Americans, and $8 \%$ of other races. The groups did not differ on the main sociodemographic characteristics, except that men were younger than women were; therefore, analyses examining sex differences included age as a covariate.

\section{Tolerability and Adverse Events}

Naltrexone increased ratings for 2 of the fifteen adverse effects examined during the first week (Supplementary Table A, Supplemental Digital Content 2, http://links.lww.com/JCP/A141). These effects were nausea ( $48 \%$ naltrexone and $23 \%$ placebo, $P<0.01)$ and light-headedness/dizzy (53\% naltrexone and 34\% placebo, $P<0.05)$. By the fourth week, the differences between treatment groups were no longer apparent. Also, for both groups, when adverse effects were present, most participants $(>75 \%)$ rated them as mild. There were no sex differences in adverse effects ratings. Because nausea has been the most commonly reported naltrexone adverse effect, we repeated the analyses of main outcomes presented in this section by covarying for nausea, and results did not change. There were 2 serious adverse events reported in each group during active treatment (naltrexone: benign brain mass, suicidal ideation remitting in 2 days with recurrence; placebo: lung cancer, motor vehicle collision).

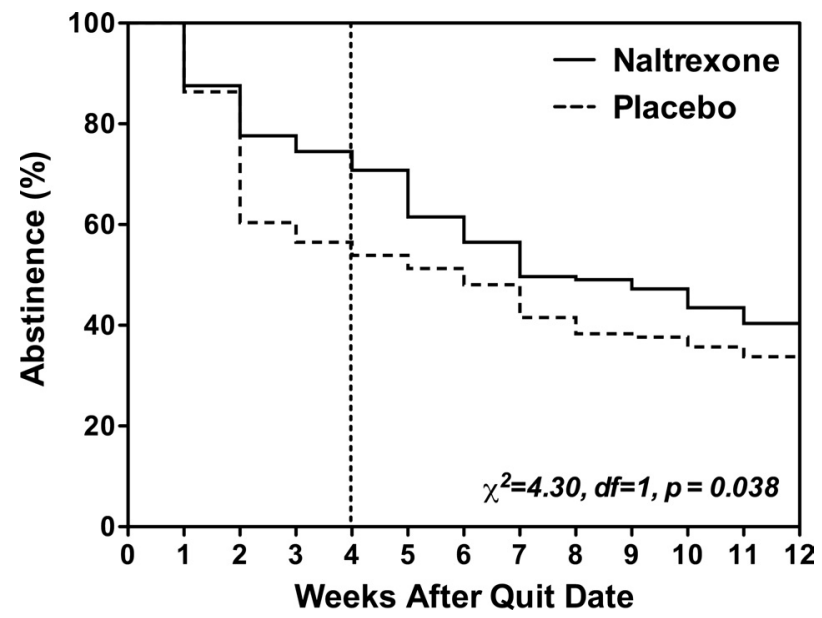

FIGURE 1. Survival curve: Kaplan-Meier survival functions for naltrexone (solid line) and placebo (dotted line) groups. The naltrexone group had significantly better survival (not smoking for seven days on a row and not smoking in one day on each of two consecutive weeks) than the placebo group (Wilcoxon-Breslow test).

\section{Quit Rates}

For the overall sample, survival analysis revealed that compared with placebo, naltrexone significantly improved lapseallowed quit rates over the course of the 12 weeks of treatment $\left(\chi_{1}^{2}=4.30, P<0.05\right.$; Fig. 1$)$. Naltrexone also improved quit rates by the more stringent prolonged abstinence criteria $\left(\chi^{2}=\right.$ $3.6, \mathrm{df}=1, P=0.057)$. In addition, naltrexone delayed time to first cigarette (21.0 days for naltrexone and 15.2 days for placebo; $\left.t_{242}=2.24, P<0.05\right)$ and reduced the number of cigarettes smoked during active treatment $(\beta[\mathrm{SE}]=-0.02[0.01], P=0.05)$.

\section{Weight Gain}

Naltrexone significantly reduced the amount of weight gained at the end of treatment for the whole sample regardless of quit status, with a mean \pm SEM of $3.42 \pm 0.53 \mathrm{lb}$ gained in the naltrexone group compared with $5.29 \pm 0.52 \mathrm{lb}$ gained in the placebo group $\left(t_{219}=2.52, P<0.05\right)$. Among the approximately one third of participants who were abstainers at the end of treatment, naltrexone also significantly reduced weight gain, with a mean \pm SEM of $4.98 \pm 0.75 \mathrm{lb}$ gained in those treated with naltrexone compared with $7.31 \pm 0.71 \mathrm{lb}$ gained in those treated with placebo $\left(t_{106}=2.23, P<0.05\right)$.

\section{Sex Differences}

Analyses comparing the sexes revealed that naltrexone improved end of treatment prolonged abstinence quit rates and reduced number of cigarettes smoked in men but not in women $(P<0.05$; Table 2$)$. In contrast, naltrexone reduced the amount of weight gained at the end of treatment in women but not in men (Table 2). The latter was observed for both the whole sample and in the subgroup of abstainers only $(\beta[\mathrm{SE}]=0.14$ [0.07], $P=0.04)$.

\section{Smoking Urge and Depressive Symptoms}

Although both groups showed decreases in smoking urge scores through treatment, the reductions were larger in the naltrexone group, with an average Brief Questionnaire of Smoking Urge scale score decrease of $13.6 \pm 1.17$ points in the naltrexone 
TABLE 2. Quit Rates, Cigarettes Smoked Weekly, and Weight Gain at the End of Treatment (12 Weeks)

\begin{tabular}{|c|c|c|c|c|c|c|}
\hline \multirow[b]{2}{*}{ Outcome } & \multicolumn{2}{|c|}{ Men } & \multicolumn{2}{|c|}{ Women } & \multirow[b]{2}{*}{ Interaction Term } & \multirow[b]{2}{*}{$\boldsymbol{P}$} \\
\hline & Naltrexone & Placebo & Naltrexone & Placebo & & \\
\hline Quit rate, n (\%) & $30 \%(23 / 76)$ & $17 \%(12 / 71)$ & $20 \%(17 / 85)$ & $28 \%(23 / 83)$ & $\begin{array}{c}\text { Med } \times \text { Sex } \\
\text { OR }(\mathrm{CI})=3.33(1.14 \text { to } 9.71)\end{array}$ & 0.027 \\
\hline Cigarettes smoked weekly, mean (SE) & $31.8(5.43)$ & $49.5(6.73)$ & $38.8(5.14)$ & $37.7(5.48)$ & $\begin{array}{c}\text { Med } \times \text { Sex } \times \text { Time } \\
\beta(C I)=-0.11(-0.16 \text { to } 0.05)\end{array}$ & $<0.001$ \\
\hline Weight gain, lb, mean (SE) & $4.79(0.78)$ & $5.58(0.78)$ & $2.26(0.68)$ & $5.08(0.69)$ & $\begin{array}{c}\text { Med } \times \text { Sex } \times \text { Time } \\
\beta(\mathrm{CI})=0.20(0.03 \text { to } 0.38)\end{array}$ & 0.020 \\
\hline
\end{tabular}

Quit rate is based on prolonged abstinence criteria (not smoking even 1 puff of a cigarette allowing a 1-week grace period).

Cigarettes smoked weekly (after log transformation) and weight gain were analyzed by generalized estimating equations. Time includes each week during the 12 week of active treatment.

All analyses controlled for age.

$\beta(\mathrm{CI})$ : coefficients and $95 \%$ confidence interval for the medication $\times$ sex or medication $\times$ sex $\times$ time interaction term in regression models for weight gain

group compared with $9.58 \pm 1.39$ points in the placebo group $(\beta[\mathrm{SE}]=-4.37$ [2.05], $P<0.05)$. Because current major depression was an exclusion criterion in the study, most participants had non-clinically significant baseline Beck Depression Inventory scores (Table 1); scores decreased further through treatment, with average ratings through treatment of $2.45 \pm 0.37$ in the naltrexone group compared with $2.78 \pm 0.35$ in the placebo group $(\beta[\mathrm{SE}]=0.50$ [0.57], $P=0.38)$. There were no main effects of sex or interactions of sex with medication on these outcomes.

\section{Follow-Up Period}

Analysis of 7-day point prevalence abstinence at follow-up showed that naltrexone and placebo groups did not differ either at 26 weeks ( $26 \%$ quit rate in both groups) or at 52 weeks $(17 \%$ naltrexone vs $23 \%$ placebo quit rate). Quit rates during followup did not differ by sex. There were 10 serious adverse events reported during follow-up, 5 in each group (placebo: cancerous lung mass surgery [same participant as during treatment], prolapsed rectum, glaucoma surgery, pneumonia, and kidney failure; naltrexone: brain mass surgery [same participant as during treatment], pneumonia [2 participants], appendectomy, and pancreatitis).

\section{DISCUSSION}

In the current study, naltrexone produced several beneficial effects in the treatment of nicotine dependence. For the whole sample, naltrexone improved quit rates, increased time to first cigarette, reduced cigarettes smoked and smoking urge ratings, and lessened the amount of weight gained. Once the medication was discontinued, the smoking quit rate benefit of naltrexone was no longer present at follow up. When the end-of-treatment results were analyzed by sex, men showed greater naltrexone-related improvement in quit rates and reduction in smoking, whereas women showed a lessening in weight gain (ie, $50 \%$ weight gain reduction).

Weight gain is common during smoking cessation ${ }^{3}$ and may be a more salient issue for women smokers given their body dissatisfaction and concerns about gaining weight with cessation. ${ }^{22}$ Indeed, weight gain after cessation is paradoxically a negative consequence of quitting, as it may add to the already high obesity rates in the United States, ${ }^{41}$ where it is second only to tobacco as a leading cause of death in this country. ${ }^{42}$ The endogenous opioid system represents a compelling neurobiological target for weight problems because opioid peptides are involved in hedonic effects of eating and opioid receptor antagonists suppress food consumption in binge eaters. ${ }^{43}$ Why men were less sensitive than women were on the effects of naltrexone on weight gain is unclear, but it is possible that there are sex differences in opioid reward pathways for eating behaviors or behavioral processes of food intake. Although the results support the use of $50 \mathrm{mg}$ of oral naltrexone to reduce postcessation weight gain, ${ }^{5,6}$ particularly for women, ${ }^{19}$ larger studies and over longer intervals are needed to draw conclusions on longer-term effects.

The benefits of naltrexone on smoking in men versus women cannot be explained by study adherence because the sexes did not differ on tablet or patch compliance or the number of sessions attended. Men's greater sensitivity to naltrexone on smoking quit rates is similar to the results of a large multisite study $^{26}$ with injectable naltrexone showing that men had lower alcohol relapse rates than women did and is also consistent with prior results showing mens' reductions in heavy drinking with targeted oral naltrexone. ${ }^{44}$ However, no sex differences with naltrexone in alcoholics were reported in another study. ${ }^{45}$ In our preliminary smoking cessation trial, ${ }^{4}$ we did not observe that men were more sensitive to naltrexone on quit rates, but that trial had a small sample size and the duration of medication treatment was only 8 weeks. Although the benefits of naltrexone on men's smoking behaviors were observed during active treatment, this was no longer apparent after discontinuation of medication through the 1 year of follow-up. This finding suggests that longer-term treatment, gradual dosage reduction, or targeted treatment may be necessary for extended relapse prevention. ${ }^{44}$ In addition, naltrexone reduction in the number of cigarettes smoked during treatment suggests that it may be of value as a smoking reduction agent, particularly for patients who are reluctant to set a goal of abstinence. However, such harm reduction strategies should be pursued cautiously because no safe level of smoking has been identified.

The possible biobehavioral mechanisms that may account for the observed sex differences in outcomes with naltrexone may in part be due to the varying levels of sex steroids, including estrogen phase, which can alter $\mu$-opioid receptor availability, sex differences in responses based on polymorphisms of OPRM1 (which encodes the $\mu$-opioid receptor) and other gene variants, and 
differential striatal dopamine release in men and women. ${ }^{19,46-48}$ Women show less reinforcement directly through nicotine when smoking and more from nonnicotine or exteroceptive factors such as cues, emotional stimuli, and social support. ${ }^{15,49}$ Therefore, they may present with a more complex clinical picture when treated for nicotine dependence. Others have suggested that women smokers may need supplemental treatments or other novel approaches to augment smoking outcomes. ${ }^{15}$ On the basis of the current study, naltrexone reduction in women's weight gain may represent a new adjunct pharmacological strategy to facilitate more quit attempts for them through lessening their concerns and experience of cessation-related weight gain.

The strengths of the current study included the recruitment of a large and diverse sample of smokers, high completion and retention rates, and the inclusion of both quit rates and weight gain as outcomes. However, there were also several limitations, including the use of only 1 dosage of naltrexone and open-label nicotine patch for the first 4 weeks and reduced statistical power for effects in abstainers over follow-up. Although this study is the largest to date examining smokers' response to $50 \mathrm{mg}$ of naltrexone daily (ie, the FDA-approved dose for opioid and alcohol dependencies), optimal dosing remains an empirical question because there are mixed findings at the $25-\mathrm{mg} \operatorname{dose}^{6,10}$ and greater efficacy but more adverse effects and drop-outs from treatment at the $100-\mathrm{mg}$ dose. ${ }^{6}$ In nicotine replacement, we chose a shorter interval than listed by patch manufacturers because the goal was to mitigate early withdrawal-like effects ${ }^{27}$ and to reflect the duration of actual patch use by most consumers, which has been shown to be beneficial. ${ }^{33}$ Further research to examine drug interactions with specific treatment elements (eg, patch, counseling) may be warranted in dismantling studies, and extended treatment with $50 \mathrm{mg}$ of naltrexone may be important as long as adherence can be maintained for longer intervals, which can be problematic.

In conclusion, the addition of $50 \mathrm{mg}$ of oral naltrexone was well tolerated and may be efficacious for the treatment of nicotine dependence at least during the interval when medication is administered. Several interesting sex differences were apparent for naltrexone effects on quit rates and weight gain and require further research. As most smokers fail even with the most effective approved pharmacotherapies for nicotine dependence, a closer examination of naltrexone augmentation for smoking cessation treatment is warranted.

\section{ACKNOWLEDGMENTS}

Special appreciation is extended to the Respiratory Health Association of Metropolitan Chicago and the Howard Brown Health Center for their support of this study and for providing additional study sites. The authors thank Drs Rachel Torello, Michelle Wasserman, Julie Wernke, Sandra Yu Rueger, and April Jones for providing counseling; Ayodele Gomih, Michelle Carpentier, Toni Harris, and Constantine Trela for data collection and database management assistance; and Lingjiao Zhang, MS, for biostatistical and administrative assistance.

\section{AUTHOR DISCLOSURE INFORMATION}

Andrea King is part of the advisory board and is a consultant for Lundbeck and the US Food and Drug Administration. Dingcai Cao is part of the advisory board and is a consultant for the US Food and Drug Administration. Stephanie S. O'Malley received research support from NABI Biopharmaceuticals, Pfizer Inc; is part of the advisory board and is a consultant for the American College of Neuropsychopharmacogy workgroup, the Alcohol Clinical Trial Initiative Group; is sponsored by Alkermes, Abbott Laboratories, Eli Lilly \& Company, Glaxo-
SmithKline, Johnson \& Johnson Pharmaceuticals, Lundbeck, Schering Plough, Pfizer, and Gilead Pharmaceuticals. Dr O'Malley was an inventor on a patent on naltrexone for smoking cessation held by Yale University, which has been abandoned. Henry $R$. Kranzler is part of the advisory board and is a consultant for the American College of Neuropsychopharmacogy Alcohol Clinical Trial Initiative Group, Lundbeck, GlaxoSmithKline, Alkermes, Gilead, Roche, Pfizer, and Lilly. Dr Kranzler received grants from Merck. Harriet deWit received grants from Unilever. Dr deWit is part of the advisory board and is a consultant for the US Food and Drug Administration. Alicia K. Matthews is part of the advisory board and is a consultant for US Food and Drug Administration. Xiaochen Cai and Ryan J. Stachoviak report no financial conflicts of interest.

\section{REFERENCES}

1. Cigarette smoking among adults and trends in smoking cessation-United States, 2008. MMWR Morb Mortal Wkly Rep. 2009;58(44):1227-1232.

2. Annual smoking-attributable mortality, years of potential life lost, and economic costs - United States, 1995-1999. MMWR Morb Mortal Wkly Rep. 2002;51(14):300-303.

3. Fiore MC, Jaén CR, Baker TB, et al. Treating Tobacco Use and Dependence: 2008 Update. Clinical Practice Guideline. Rockville, MD: US Department of Health and Human Services, Public Health Service; 2008.

4. Berridge KC, Ho CY, Richard JM, et al. The tempted brain eats: pleasure and desire circuits in obesity and eating disorders. Brain Res. 2010;1350:43-64.

5. King A, de Wit H, Riley RC, et al. Efficacy of naltrexone in smoking cessation: a preliminary study and an examination of sex differences. Nicotine Tob Res. 2006;8(5):671-682.

6. O’Malley SS, Cooney JL, Krishnan-Sarin S, et al. A controlled trial of naltrexone augmentation of nicotine replacement therapy for smoking cessation. Arch Intern Med. 2006;166(6):667-674.

7. King A, Torello R, Krishnan-Sarin S, et al. Naltrexone in smoking cessation: a review of the literature and future directions. In: Dean R, Bilsky E, Negus S, eds. Opiate Receptors and Antagonists. Belmont, MA: Springer; 2009:307-324.

8. Fiore MC, Jorenby DE, Baker TB, et al. Tobacco dependence and the nicotine patch. Clinical guidelines for effective use. JAMA. 1992;268(19):2687-2694.

9. Wong GY, Wolter TD, Croghan GA, et al. A randomized trial of naltrexone for smoking cessation. Addiction. 1999;94(8):1227-1237.

10. Toll BA, White M, Wu R, et al. Low-dose naltrexone augmentation of nicotine replacement for smoking cessation with reduced weight gain: a randomized trial. Drug Alcohol Depend. 2010;111(3):200-206.

11. David SP, Lancaster T, Stead LF, et al. Opioid antagonists for smoking cessation (review). Cochrane Database Syst Rev. 2009;(4):CD003086.

12. Covey LS, Glassman AH, Stetner F. Naltrexone effects on short-term and long-term smoking cessation. J Addict Dis. 1999;18(1):31-40.

13. Byars JA, Frost-Pineda K, Jacobs WS, et al. Naltrexone augments the effects of nicotine replacement therapy in female smokers. $J$ Addict Dis. 2005;24(2):49-60.

14. Munafo M, Bradburn M, Bowes L, et al. Are there sex differences in transdermal nicotine replacement therapy patch efficacy? A meta-analysis. Nicotine Tob Res. 2004;6(5):769-776. 
15. Perkins KA, Scott J. Sex differences in long-term smoking cessation rates due to nicotine patch. Nicotine Tob Res. 2008;10(7):1245-1250

16. Smith YR, Stohler CS, Nichols TE, et al. Pronociceptive and antinociceptive effects of estradiol through endogenous opioid neurotransmission in women. $J$ Neurosci. 2006;26(21): 5777-5785.

17. Zubieta JK, Smith YR, Bueller JA, et al. mu-Opioid receptor-mediated antinociceptive responses differ in men and women. $J$ Neurosci. 2002;22(12):5100-5107.

18. Roche DJ, Childs E, Epstein AM, et al. Acute HPA axis response to naltrexone differs in female vs. male smokers. Psychoneuroendocrinology. 2010;35(4):596-606.

19. Epperson $\mathrm{CN}$, Toll B, Wu R, et al. Exploring the impact of gender and reproductive status on outcomes in a randomized clinical trial of naltrexone augmentation of nicotine patch. Drug Alcohol Depend. 2010;112(1-2):1-8.

20. Jo YH, Talmage DA, Role LW. Nicotinic receptor-mediated effects on appetite and food intake. $J$ Neurobiol. 2002;53(4):618-632.

21. Klesges RC, DeBon M, Vander Weg MW, et al. Efficacy of a tailored tobacco control program on long-term use in a population of U.S. military troops. J Consult Clin Psychol. 2006;74(2): 295-306.

22. Sanchez-Johnsen LA, Carpentier MR, King AC. Race and sex associations to weight concerns among urban African American and Caucasian smokers. Addict Behav. 2011;36(1-2):14-17.

23. Mizes JS, Sloan DM, Segraves K, et al. The influence of weight-related variables on smoking cessation. Behav Ther. 1998;29(3):371-385.

24. Pecina S, Smith KS. Hedonic and motivational roles of opioids in food reward: implications for overeating disorders. Pharmacol Biochem Behav. 2010;97(1):34-46.

25. Yeomans MR, Gray RW. Opioid peptides and the control of human ingestive behaviour. Neurosci Biobehav Rev. 2002;26(6):713-728.

26. Weerts EM, Kim YK, Wand GS, et al. Differences in delta- and mu-opioid receptor blockade measured by positron emission tomography in naltrexone-treated recently abstinent alcohol-dependent subjects. Neuropsychopharmacology. 2008;33(3):653-665.

27. Krishnan-Sarin S, Rosen MI, O’Malley SS. Naloxone challenge in smokers. Preliminary evidence of an opioid component in nicotine dependence. Arch Gen Psychiatry. 1999;56(7):663-668.

28. Cummings KM, Giovino G, Jaen CR, et al. Reports of smoking withdrawal symptoms over a 21 day period of abstinence. Addict Behav. 1985;10(4):373-381.

29. King AC, Meyer PJ. Naltrexone alteration of acute smoking response in nicotine-dependent subjects. Pharmacol Biochem Behav. 2000;66(3):563-572.

30. King AC, Cao D, Southard CC, et al. Racial differences in eligibility and enrollment in a smoking cessation clinical trial. Health Psychol. 2011;30(1):40-48.

31. Heatherton TF, Kozlowski LT, Frecker RC, et al. The Fagerström Test for Nicotine Dependence: a revision of the Fagerström Tolerance Questionnaire. Br J Addict. 1991;86(9):1119-1127.

32. First MB, Spitzer RL, Gibbon M, et al. Structured Clinical Interview for DSM-IV Axis I Disorders, Research Version, Non-patient
Edition. New York, NY: Biometrics Research, New York State Psychiatric Institute; 2002.

33. Pierce JP, Gilpin EA. Impact of over-the-counter sales on effectiveness of pharmaceutical aids for smoking cessation. JAMA. 2002;288(10):1260-1264.

34. King A, Sanchez-Johnsen L, Van Orman S, et al. A pilot community-based intensive smoking cessation intervention in African Americans: feasibility, acceptability and early outcome indicators. J Natl Med Assoc. 2008;100(2):208-217.

35. Sobell LC, Sobell MB. Timeline Follow Back: A Calendar Method for Assessing Alcohol and Drug Use (User's Guide). Toronto, Canada: Addiction Research Foundation; 1996.

36. Cox LS, Tiffany ST, Christen AG. Evaluation of the brief questionnaire of smoking urges (QSU-brief) in laboratory and clinical settings. Nicotine Tob Res. 2001;3(1):7-16.

37. Beck AT, Ward CH, Mendelson M, et al. An inventory for measuring depression. Arch Gen Psychiatry. 1961;4(6):561-671.

38. Hughes JR, Keely JP, Niaura RS, et al. Measures of abstinence in clinical trials: issues and recommendations. Nicotine Tob Res. 2003;5(1):13-25.

39. Javors MA, Hatch JP, Lamb RJ. Cut-off levels for breath carbon monoxide as a marker for cigarette smoking. Addiction. 2005;100(2):159-167.

40. Zeger SL, Liang KY, Albert PS. Models for longitudinal data: a generalized estimating equation approach. Biometrics. 1988;44(4):1049-1060.

41. Stewart ST, Cutler DM, Rosen AB. Forecasting the effects of obesity and smoking on U.S. life expectancy. $N$ Engl J Med. 2009;361(23):2252-2260.

42. Stein CJ, Colditz GA. The epidemic of obesity. J Clin Endocrinol Metab. 2004;89(6):2522-2525.

43. Drewnowski A, Krahn DD, Demitrack MA, et al. Naloxone, an opiate blocker, reduces the consumption of sweet high-fat foods in obese and lean female binge eaters. Am J Clin Nutr. 1995;61(6):1206-1212.

44. Kranzler HR, Tennen H, Armeli S, et al. Targeted naltrexone for problem drinkers. J Clin Psychopharmacol. 2009;29(4):350-357.

45. Greenfield SF, Pettinati HM, O’Malley S, et al. Gender differences in alcohol treatment: an analysis of outcome from the COMBINE study. Alcohol Clin Exp Res. 2010;34(10):1803-1812.

46. Urban NB, Kegeles LS, Slifstein M, et al. Sex differences in striatal dopamine release in young adults after oral alcohol challenge: a positron emission tomography imaging study with $\left[{ }^{11}\right.$ C]raclopride. Biol Psychiatry. 2010;68(8):689-696.

47. Rukstalis M, Jepson C, Strasser A, et al. Naltrexone reduces the relative reinforcing value of nicotine in a cigarette smoking choice paradigm. Psychopharmacology (Berl). 2005;180(1):41-48.

48. Smith YR, Zubieta JK, del Carmen MG, et al. Brain opioid receptor measurements by positron emission tomography in normal cycling women: relationship to luteinizing hormone pulsatility and gonadal steroid hormones. J Clin Endocrinol Metab. 1998;83(12):4498-4505.

49. Perkins KA. Smoking cessation in women. Special considerations. CNS Drugs. 2001;15(5):391-411. 